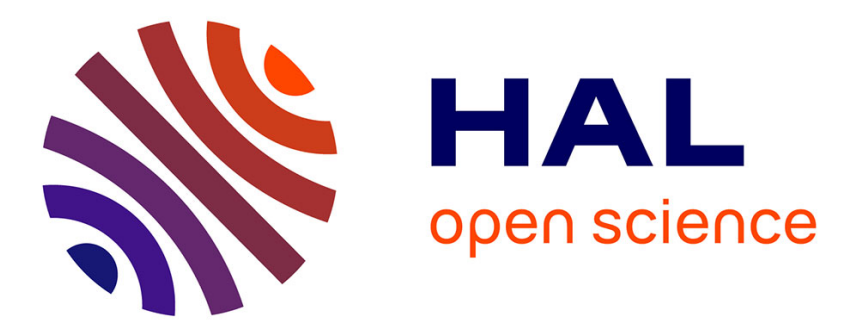

\title{
EPR study of the cis-trans isomerization process in polyacetylene films
}

\author{
P. Bernier, C. Linaya, M. Rolland, M. Aldissi
}

\section{To cite this version:}

P. Bernier, C. Linaya, M. Rolland, M. Aldissi. EPR study of the cis-trans isomerization process in polyacetylene films. Journal de Physique Lettres, 1981, 42 (13), pp.295-299. 10.1051/jphyslet:019810042013029500 . jpa-00231931

\section{HAL Id: jpa-00231931 https://hal.science/jpa-00231931}

Submitted on 1 Jan 1981

HAL is a multi-disciplinary open access archive for the deposit and dissemination of scientific research documents, whether they are published or not. The documents may come from teaching and research institutions in France or abroad, or from public or private research centers.
L'archive ouverte pluridisciplinaire HAL, est destinée au dépôt et à la diffusion de documents scientifiques de niveau recherche, publiés ou non, émanant des établissements d'enseignement et de recherche français ou étrangers, des laboratoires publics ou privés. 


\title{
EPR study of the cis-trans isomerization process in polyacetylene films
}

\author{
P. Bernier (*), C. Linaya (**), M. Rolland (*) and M. Aldissi (**) \\ (*) Groupe de Dynamique des Phases Condensées (***), \\ (**) Laboratoire de Chimie Macromoléculaire, \\ USTL, place Eugène-Bataillon, 34060 Montpellier, France
}

(Reçu le 3 mars 1981, accepté le 12 mai 1981)

\begin{abstract}
Résumé. - En utilisant la RPE nous avons étudié le processus d'isomérisation qui conduit, par traitement thermique, des films de cis- $(\mathrm{CH})_{x}$ à la configuration trans. En suivant les comportements avec le temps et la température des largeurs de raie et nombre de spins mesurés, nous avons montré que pour les températures les plus basses

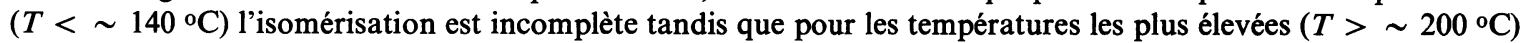
la dégradation du système devient de plus en plus efficace. Il existe un étroit domaine de température $(T \sim 140$ à $150^{\circ} \mathrm{C}$ ) où des caractéristiques optimales (isomérisation totale + faible dégradation) peuvent être obtenues.
\end{abstract}

\begin{abstract}
Using EPR we have studied the isomerization process converting cis- $(\mathrm{CH})_{x}$ films to the trans form upon thermal treatment. Following the measured linewidth and number of spins versus time and temperature, it is shown that for the lowest temperatures $\left(T<\sim 140^{\circ} \mathrm{C}\right)$ isomerization cannot be complete while for the highest ones $\left(T>\sim 200^{\circ} \mathrm{C}\right)$ degradation becomes more and more efficient. There exists a small temperature range $\left(T \sim 140-150^{\circ} \mathrm{C}\right)$ where optimal characteristics (total isomerization + small degradation) can be achieved.
\end{abstract}

1. Introduction. - The increasing interest in the physical properties of doped polyacetylene is largely justified by its remarkable electric and magnetic properties. A considerable amount of work has been done on lightly and heavily doped $(\mathrm{CH})_{x}[1]$, but there exists much less data on the properties of the thermal isomerization process which brings the unstable cis- $(\mathrm{CH})_{x}$ to the stable trans configuration.

The magnetic properties of undoped polyacetylene are largely dependent on the cis/trans content [2]. It is now well established that there are no unpaired electrons in the as-prepared pure cis- $(\mathrm{CH})_{x}\left(\right.$ at $\left.-78^{\circ} \mathrm{C}\right)$ as evidenced by the absence of any EPR signal [3]. The presence of unpaired electrons is directly related to the trans content, following for instance a thermal treatment. Weinberger et al. [4] proposed that such electrons could be associated with $\pi$ phase kinks appearing in the trans configuration and absent in the cis one. Furthermore, Chien et al. [5] have shown that the mechanisms of kink formation and configurational isomerization were intimately related. EPR is then an appropriate technique in order to study the isomerization kinetics.

Weinberger et al. [4] have assumed that the observed EPR linewidth of trans- $(\mathrm{CH})_{x}$ was due to unresolved

(***) Laboratoire associé au C.N.R.S hyperfine interaction between the delocalized electrons and the neighbouring protons of the chains. Nevertheless, in very recent work, Holczer et al. [6] have shown that part of the linewidth was due to localized unpaired electrons, probably connected with the presence of a small amount of oxygen, even in the cleanest samples (for instance oxygen coming from catalytic residues). It is then clear that, in order to study the physical properties of the only mobile electrons, the EPR linewidth is not the best parameter to look at. The same remark can be made concerning the number of spins, which is the sum of the delocalized and localized electron contributions. Nevertheless, if one considers the fact that the number of localized unpaired electrons is originally fixed and does not strongly depend on further treatments in the temperature range we are going to investigate, it can be assumed that the relative variations of the EPR linewidth and number of spins are representative of the behaviour of the mobile electrons only. Qualitative information can then be gained about the isomerization process during which the extent of mobility of the electrons delocalized on the trans sequences is expected to vary.

Another process which can strongly affect the mobility of the unpaired electrons is degradation of the polymer. Rolland et al. [7] have found evidence for such a degradation in a study of the electrical conductivity during a thermal treatment of cis- $(\mathrm{CH})_{x}$ : 
for temperatures $T>\sim 140^{\circ} \mathrm{C}$, the conductivity first increases as the isomerization occurs, and then decreases after a given time (which decreases with increasing temperature). Creation of crosslinks between chains is a very likely degradation process as it is known that trans- $(\mathrm{CH})_{x}$ is practically unstretchable [8]. Such crosslinks reduce the mean length of the trans sequences with a consequent decrease in electron mobility. Such a degradation is then expected to be detectable using EPR.

In this paper we present an experimental study of the isomerization and degradation processes, during a thermal treatment of cis- $(\mathrm{CH})_{x}$. We have followed the variations of the EPR linewidth and of the number of spins versus time and temperature. Our goal is to determine, in connection with the conductivity results of Rolland et al. [7], the optimal conditions for isomerization with the smallest amount of degradation. We also try to analyse the degradation process in order to determine its thermodynamic characteristics.

2. Experimental conditions. - Polyacetylene films were obtained by the method described by Ito et al. [9], at $-78^{\circ} \mathrm{C}$. The cis-rich films obtained, with typical thickness $\sim 100 \mu$, were kept at $-30^{\circ} \mathrm{C}$ until the measurement. At room temperature the cis content of the samples, as determined by infrared spectroscopy, was typically $96 \%$. A small strip of the films $(\sim 2 \mathrm{mg})$ was then introduced into the EPR tube and sealed under a very clean atmosphere of nitrogen.

The EPR spectra have been recorded on an ER10 Bruker spectrometer working at $9.0 \mathrm{GHz}$. The microwave power could be varied between 0.5 and $30 \mathrm{~mW}$. In the following, the experiments have been generally performed with the smallest available power $(<1 \mathrm{~mW})$ in order to avoid any saturation effects [6].

A flow of heated dry air was passed through an insulated quartz tube inside the cavity. The temperature of the sample could be varied between room temperature and $325^{\circ} \mathrm{C}$. Its absolute value was determined by direct reading of the apparatus, correctly calibrated. The accuracy was estimated to be of the order of $\pm 2^{\circ} \mathrm{C}$. The long term stability of the temperature was better than $1^{\circ} \mathrm{C}$. The time required to thermalyze the sample has been estimated of the order of $10 \mathrm{~s}$ at $200^{\circ} \mathrm{C}$. In all cases it was much shorter than the time required for recording the spectrum ( $10 \mathrm{~min}$.).

The linewidth $\Delta H_{\mathrm{pp}}$ is defined as the distance in Gauss between the peaks of the absorption derivative. We have not determined the absolute value of the number $N$ of observed spins, but followed the variations of the relative number $N / N_{0}$ where $N_{0}$ refers to the number of spins just before the isomerization process.

3. Experimental results. - On the figure 1, the variations with time $t$ of the measured linewidth $\Delta H_{\mathrm{pp}}$ are reported for various cis-rich $(\mathrm{CH})_{x}$ films which have been heated at various fixed temperatures

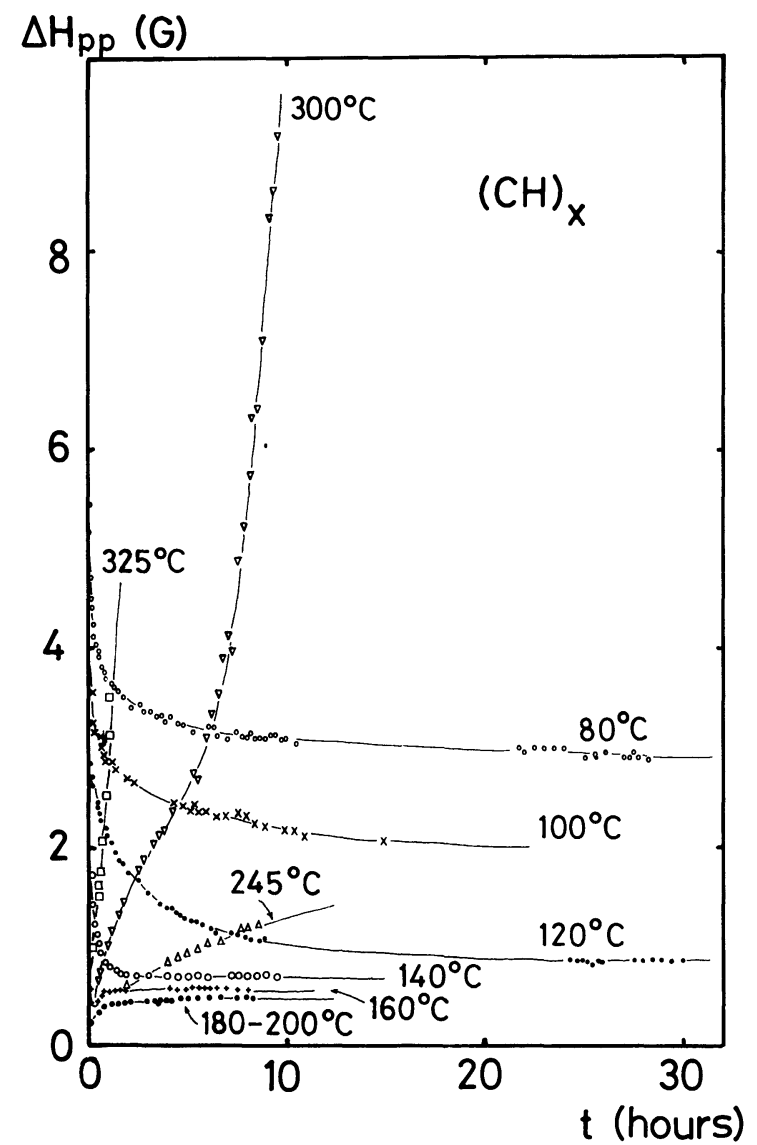

Fig. 1. - Dependence with time $t$ of the measured peak to peak EPR linewidth $\Delta H_{\mathrm{pp}}$, at various temperatures. The starting material at $t=0$ is $95 \%$ cis- $(\mathrm{CH})_{x}$. Each experimental curve is obtained at the indicated temperature.

$T_{\mathrm{tt}}$. Starting at $t=0$ from the value $\Delta H_{\mathrm{pp}} \sim 8$ gauss characteristic of the cis-rich $(\mathrm{CH})_{x}[2,10,11]$, we observe at all temperatures very strong variations of the measured linewidth. We can roughly define three temperature ranges :

(i) $T_{\mathrm{tt}}<140^{\circ} \mathrm{C}$. In this range $\Delta H_{\mathrm{pp}}$ decreases monotonically with $t$, reaching a constant value after a long time (typically $\sim 24$ hours). This constant value decreases when we increase the temperature $T_{\mathfrak{t}}$ of the thermal treatment.

(ii) $140^{\circ} \mathrm{C}<T_{\mathrm{tt}}<200^{\circ} \mathrm{C}$. After a rapid decrease, $\Delta H_{\mathrm{pp}}$ goes through a slight minimum to increase again and saturate at a constant value. The time at which the minimum occurs is of the order of $15 \mathrm{~min}$. at $160^{\circ} \mathrm{C}$ and decreases with increasing temperature. The constant linewidth value attained after a long time is considerably less temperature dependent than in the previous range.

(iii) $T_{\mathrm{tt}}>200^{\circ} \mathrm{C}$. In this range the decrease of $\Delta H_{\mathrm{pp}}$ for short times is so rapid that it cannot be measured. We only observe a monotonic increase of linewidth with time, the slope of which increases with increasing temperature. Finally, for temperatures higher than $325^{\circ} \mathrm{C}$, the film rapidly decomposes [2]. 
In the preceding variations, two distinct effects are superimposed :

(i) The effect of the isomerization process which is known to lead to a decrease of $\Delta H_{\mathrm{pp}}$ [2].

(ii) The decrease of $\Delta H_{\mathrm{pp}}$ with increasing temperature which is observed even when a stable configuration of the polymer is attained [4]. We must note that the linewidth variation due to the isomerization process is much larger than the one due to the pure thermal effect.

In order to study the first effect and to avoid the second one, we have performed the following experiment. Various cis-rich $(\mathrm{CH})_{x}$ films coming from the same initial film have been heated at various temperatures $T_{\mathrm{tt}}$ during a time long enough (between 10 and 15 hours) to attain a stable linewidth value $\left({ }^{1}\right)$. Then the samples have been rapidly cooled to room temperature and the EPR spectra recorded. The figure 2 then reports the variations of the measured linewidth at

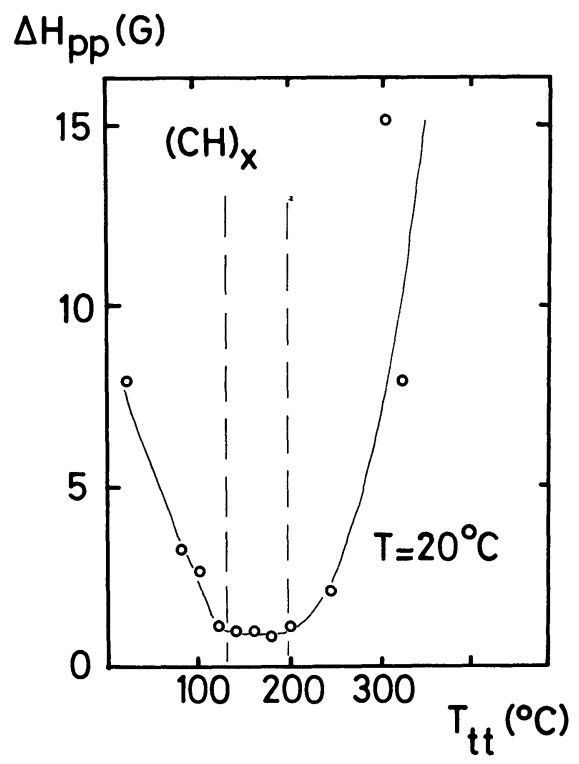

Fig. 2. - Dependence with the temperature $T_{\mathrm{tt}}$ of the thermal treatment of cis- $(\mathrm{CH})_{x}$ for $\Delta H_{\mathrm{pp}}$ measured at room temperature and obtained after a long enough time ( $\sim 10$ hours) in order to reach an apparently stable situation (but not for $T_{\mathrm{tt}}>200^{\circ} \mathrm{C}$, see footnote in the text).

room temperature versus the temperature at which the sample has been heated. The three preceding temperature ranges are again evidenced :

(i) $T<\sim 140^{\circ} \mathrm{C}, \Delta H_{\mathrm{pp}}$ decreases from $\sim 8$ gauss $\left(20^{\circ} \mathrm{C}\right)$ to $\sim 0.9$ gauss $\left(120^{\circ} \mathrm{C}\right)$.

(ii) $140<T<200^{\circ} \mathrm{C}, \Delta H_{\mathrm{pp}}$ is roughly constant at $\sim 0.8$ gauss.

(iii) $T>200^{\circ} \mathrm{C}, \Delta H_{\mathrm{pp}}$ increases very rapidly with temperature.

( $\left.{ }^{1}\right)$ We must note that for $T_{\mathrm{tt}}>200^{\circ} \mathrm{C}$ no stable situation could be attained. Then the $\Delta H_{\mathrm{pp}}$ values we have reported in this temperature range for $t=10$ or 15 hours are only indicative of a very strong and rapid increase in linewidth.
Finally we have studied the variation with time of the observed number of spins during the thermal treatments. Figure 3 shows the variation of $N\left(t, T_{\mathrm{tt}}\right) / N\left(0, T_{\mathrm{tt}}\right)$, where $N\left(t, T_{\mathrm{tt}}\right)$ represents the number of spins at time $t$ during a treatment at temperature $T_{\mathrm{tt}}$. For clarity only four temperatures have been reported in figure 3. Nevertheless, from the complete data, three distinct types of behaviour have been observed :

(i) $T<\sim 140^{\circ} \mathrm{C}$ : the relative number of spins increases monotonically to reach a constant, stable value after a long time ( $>15$ hours).

(ii) $140<T<200^{\circ} \mathrm{C}$ : after a rapid increase, the relative number of spins slightly decreases to stabilize at (approximately) a constant value after a long time.

(iii) $T>200^{\circ}$ : we only observe a rapid decrease of the relative number of spins. After a long time, the EPR signal has almost disappeared.

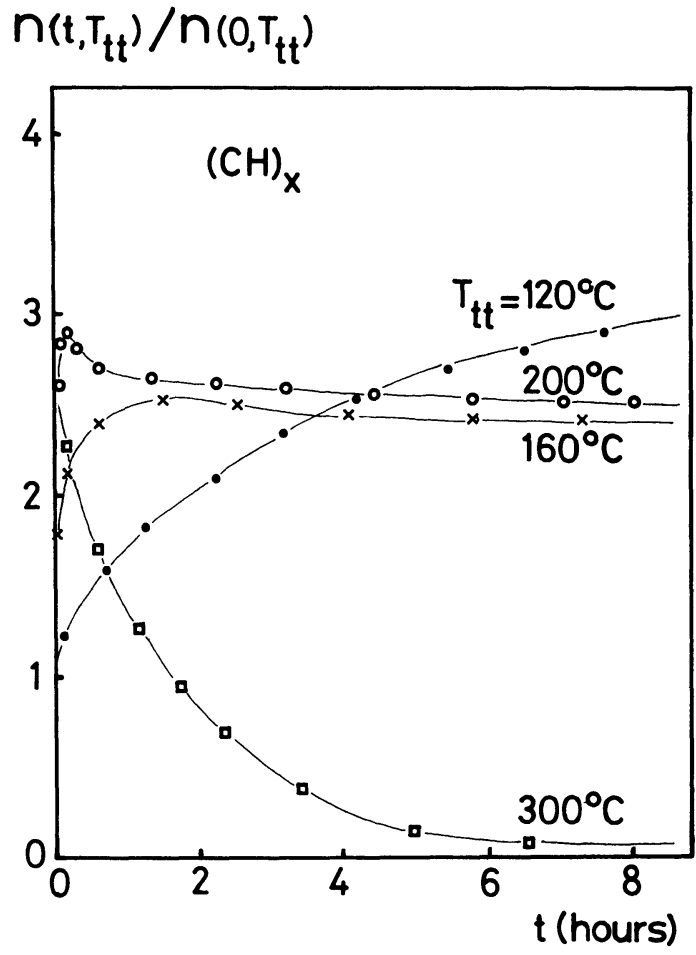

Fig. 3. - Variation with time $t$ of the number of spins $N\left(t, T_{\mathrm{t}}\right)$ normalized to the value observed at $t=0$ and at temperature $T_{\mathrm{tt}}$.

4. Discussion. - We start from the fact that the unpaired electrons which are observed at room temperature (or higher) by EPR correspond to those electrons described by Su et al. [12] in the scope of the soliton model. Such mobile electrons exist in $(\mathrm{CH})_{x}$ only on trans sequences with appreciable length ( $>20$ carbon atoms). Holczer et al. [6] have shown that the corresponding EPR linewidth $\Delta H_{\mathrm{pp}}$ can be related to the electron mobility through the electronic diffusion coefficient $D_{\|}$along the chains. The greater the mobility, the smaller the linewidth. Variations of 
$D_{\|}$(and correspondingly of $\Delta H_{\mathrm{pp}}$ ) can be induced by two ways :

(i) By a variation of the trans sequence lengths on which the electron move.

(ii) By a variation of the temperature which modify the extent of mobility of the electron. The EPR linewidth variations which are reported on figure 1 , are a superposition of these two effects. On the other hand in the case of figure 2 each sample used has been « frozen " (at room temperature) in a state characteristic of the temperature at which it has been first heated. The reported linewidths are then to be related to electron mobilities which are controlled only by the variations of the trans sequence lengths induced by the thermal treatment.

For $T<140{ }^{\circ} \mathrm{C}$, the observed decrease of $\Delta H_{\mathrm{pp}}$ with increasing $T_{\mathrm{tt}}$ (Fig. 2) down to the minimum of $\sim 0.8$ gauss at $140^{\circ} \mathrm{C}$, indicates that the isomerization is incomplete. This is consistent with I.R. [13] and Raman [14] results which show that at a given temperature a given, stable cis amount remains even after a long time. These results agree with the fact, pointed out by Shirakawa [2], that the activation energy of the isomerization process increases when the trans content of the starting $(\mathrm{CH})_{x}$ increases. It is argued that such a behaviour is connected with the fact that isomerization of a whole cis- $(\mathrm{CH})_{x}$ chain implies a collective motion which is hindered by the surrounding chains. We also note that the chain length distribution is very large as evidenced by the very large lines observed by Raman spectroscopy in the trans- $(\mathrm{CH})_{x}$ [14].

At $T \cong 140^{\circ} \mathrm{C}$ we observe our minimum linewidth value of the order of 0.8 gauss (at room temperature). At such a temperature the system is totally trans after, say two hours, as evidenced by I.R. [13] and Raman [14]. We note that our minimum $\Delta H_{\mathrm{pp}}$ value for the trans is significantly larger than the one reported by Holczer et al. [6] of the order of 0.44 gauss, obtained after a usual thermal treatment. It is even greater than the value ( 0.28 gauss) recently observed by François et al. [15] for a trans-(CH) $)_{x}$ films obtained by a soft $\mathrm{Na}$ doping of the cis. The reasons for such differences are not clear at this time. A small amount of oxygen or moisture present during the isomerization procedure could lead to a systematic increase of the measured linewidths, as evidenced by Bernier et al. [11] and Holczer et al. [6].

Chien et al. [5] have assumed there was a close relation between the isomerization process and the creation of unpaired electrons during the process. In their model these unpaired electrons are the result of a thermal excitation in the cis configuration. Nevertheless, $\mathrm{Su}$ [16] has noted that the number of spins which is usually observed in the trans- $(\mathrm{CH})_{x}$ (of the order of $100 \mathrm{ppm}$ ) is too large to be accounted for by thermal excitations. He has pointed out the possibility of unpaired electrons connected with the existence of chains with an odd number of carbon atoms. At this point the question which arises concerns the way a cis chain, which normally has an even number of carbon atoms, can lead to trans sequences bearing eventually an unpaired electron. We suggest that such a behaviour is possible when defects appear on the cis chains during the thermal treatment. Such defects would be principally crosslinks between chains, as it is well known that trans- $(\mathrm{CH})_{x}$ obtained after a thermal treatment of the cis is unstretchable [8]. Then we suggest that the increase in number of spins observed for $T<\sim 140^{\circ} \mathrm{C}$ (Fig. 3) is due to such a phenomenon. This situation is non-reversible, favouring the idea of the existence of intrinsic defects along the trans- $(\mathrm{CH})_{x}$ chains, rather than thermally activated defects.

For temperatures higher than $140{ }^{\circ} \mathrm{C}$ isomerization can be complete as evidenced by the fact that $\Delta H_{\mathrm{pp}}$ reaches its minimum value (Fig. 2). Such a conclusion is confirmed by I.R. and Raman results [13, 14]. On the other hand, with increasing temperature, the behaviours observed for the time dependences of $\Delta H_{\mathrm{pp}}$ and $N(t)$, which are the exact opposites of those observed during the isomerization process, indicate that a new phenomenon is taking place. The conductivity decrease [7] as well as the decrease in unpaired electron mobility (Fig. 2) which are observed in those conditions suggest the phenomenon is degradation occurring on the $(\mathrm{CH})_{x}$ chains. There is much experimental evidence of the existence of degradation during a thermal treatment of conjugated polymers. Recently Simionescu and Percec [17] as well as Cukor and Rubner [18] have studied the case of polyphenylacetylene (PPA) and found crosslinks, cyclization. aromatization and scission of the polymer main chain, during a heating above $130^{\circ} \mathrm{C}$. We suggest the case of polyacetylene is very similar. For instance, Raman results clearly show that during an extended heating

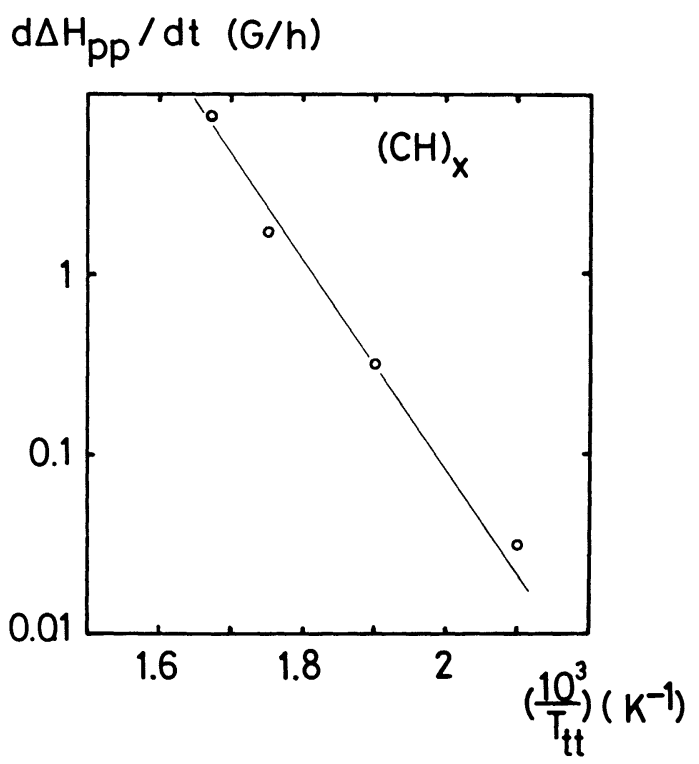

Fig. 4. - Variation with the inverse temperature $T_{\mathrm{tt}}^{-1}$ of the rate of EPR linewidth changes $\mathrm{d} \Delta H_{\mathrm{pp}} / \mathrm{d} t$ for short times $(t<2$ hours), corresponding to the experimental points of figure 1 for

$$
T_{\mathfrak{t}}>200^{\circ} \mathrm{C} \text {. }
$$


the mean length of the trans sequences decreases [14]. Also recent high resolution ${ }^{13} \mathrm{C}$ NMR experiments [19] have shown an increasing amount of $\mathrm{sp}^{3}$ hybridization after a substantial heating of the $(\mathrm{CH})_{x}$. Our present work shows that while the unpaired electron mobility is decreasing, the number of observed spins rapidly tends towards zero during a strong heating $\left(T \sim 200\right.$ to $\left.300^{\circ} \mathrm{C}\right)$. Such behaviour is consistent with the existence, during a thermal treatment, of defects on the chains which break the conjugation.

Degradation of $(\mathrm{CH})_{x}$ is even more evident for temperatures higher than $200^{\circ} \mathrm{C}$ (Figs. 1 and 2) where $\Delta H_{\mathrm{pp}}$ strongly and very rapidly increases with time while at the same time $N(t)$ decreases towards zero. The nature of the evolution and the fact that it cannot be described by a first order kinetics show that the degradation processes are probably quite complicated. Nevertheless, in order to characterize their average consequence which appears as a decrease of the average length of the trans sequences, mean lengths, we have plotted on a log scale versus $T^{-1}$ (Fig. 4) the rate at which $\Delta H_{\mathrm{pp}}$ increases for short times (see Fig. 1). The observed linear dependence allows us to deduce an activation energy for the degradation of the system of the order of $30 \mathrm{kcal} . / \mathrm{mole}$. We note that this value is substantially greater than the activation energy of the isomerization process $(18 \mathrm{kcal} . / \mathrm{mole}$ if we start with the pure cis- $\left.(\mathrm{CH})_{x}[2]\right)$. On the contrary, it is considerably smaller than the activation energies currently observed for the degradation of saturated polymers [20] (between 50 and $80 \mathrm{kcal} . /$ mole depending on the system).

5. Conclusion. - Strictly speaking, it is clear that isomerization and degradation processes always coexist. Furthermore, these two processes are probably not independent from each other. Nevertheless, from figure 2 it appears that we can define a narrow temperature window around $150^{\circ} \mathrm{C}$ where isomerization is complete while the degradation of the system can be considered as minimized.

Acknowledgments. - Support by Bruker Spectrospin France for the EPR equipment is gratefully acknowledged. This work has been supported by the "Direction des Recherches, Etudes et Techniques" under contract $\mathrm{n}^{\circ} 78 / 259$.

\section{References}

[1] The Physics and chemistry of low Dimensional Solids, ed. L. Alcacer (D. Reidel Pub. Co.) 1980.

[2] Shirakawa, H., Ito, T., Ikeda, S., Makromol. Chem. 179 (1978) 1565.

[3] Bernier, P., Rolland, M., Linayà, C., Aldissi, M., Polymer 21 (1980) 7.

Chien, J. W., Karasz, F. E., Wnek, G. E., MacDiarmid, A. G., Heeger, A. J., J. Polym. Sci. : Polym. Lett. Ed. 18 (1980) 45.

[4] Weinberger, B. R., Ehrenfreund, D., Pron, A., Hebger, A. J., MacDiarmid, A. G., J. Chem. Phys. 72 (1980) 4749.

[5] Chien, J. W., Karasz, F. E., Wnek, G. E., Capistran, J. D., to be published.

[6] Holczer, K., Boucher, J. P., DevreuX, F., Nechtschein, M., Phys. Rev., to be published.

[7] Rolland, M., Bernier, P., Lefrant, S., Aldissi, M., Polymer Comm. 21 (1980) 1111.

[8] Druy, M. A., Tsang, C. H., Brown, N., Heeger, A. J., MacDiarmid, A. G., J. Polym. Sci., Polym. Phys. Ed. 18 (1980) 429.

[9] Ito, T., Shirakawa, H., Ixeda, S., J. Polym. Sci. : Polym. Chem. Ed. 12 (1974) 11.
[10] Bernier, P., Rolland, M., Galtier, M., Montaner, A., Regis, M., Candille, M., Benoit, C., Aldissi, M., Linaya, C., Schue, F., Sledz, J., Fabre, J. M., Giral, L., J. Physique Lett. 40 (1979) L-297.

[11] Bernier, P., Rolland, M., Linaya, C., Disi, M., Sledz, J., Schue, F., Fabre, J. M., Giral, L., Polym. J., to be published.

[12] Su, W. P., Schrieffer, J. R., Heeger, A. J., Phys. Rev. B22 (1980) 5099.

[13] Montaner, A., Galtier, M., Benoit, C., Aldissi, M., preprint.

[14] Lefrant, S., Rzepka, E., Bernier, P., Rolland, M., Aldissi, M., Polymer Comm. 21 (1980) 1235.

[15] François, B., Bernard, M., André, J. J., Submitted for publication in J. Chem. Phys.

[16] Su, W. P., Solid State Commun. 35 (1980) 899.

[17] Simionescu, C. I., Percec, V., J. Polym. Sci., Polym. Chem. Ed. 18 (1980) 147.

[18] Cukor, P., Rubner, M., J. Polym. Sci., Polym. Phys. Ed. 18 (1980) 909.

[19] Bernier, P., Schue, F., Rollland, M., Aldissi, M., NechtSCHEIN, M., preprint.

[20] Thermal degradation of polymers, MADORSKY, S. L., KRIEGER, R. E. (Pub. Co.. New York) 1975 